\title{
Author Spotlight: Wendy Zhou
}

\section{Wendy Zhou ${ }^{1}$}

Accepted: 12 May 2021 / Published online: 17 June 2021

(C) The Author(s), under exclusive licence to Springer Science+Business Media, LLC, part of Springer Nature 2021

Wendy Zhou, DO is a third-year internal medicine resident at Santa Clara Valley Medical Center. She received her undergraduate degree from the University of California Berkeley and her medical degree from Touro University California. She will be graduating from her internal medicine residency this year, completing a one-year fellowship in autonomic and neurogastroenterology at Stanford. She hopes to pursue a fellowship in gastroenterology with a focus in neurogastroenterology and motility.

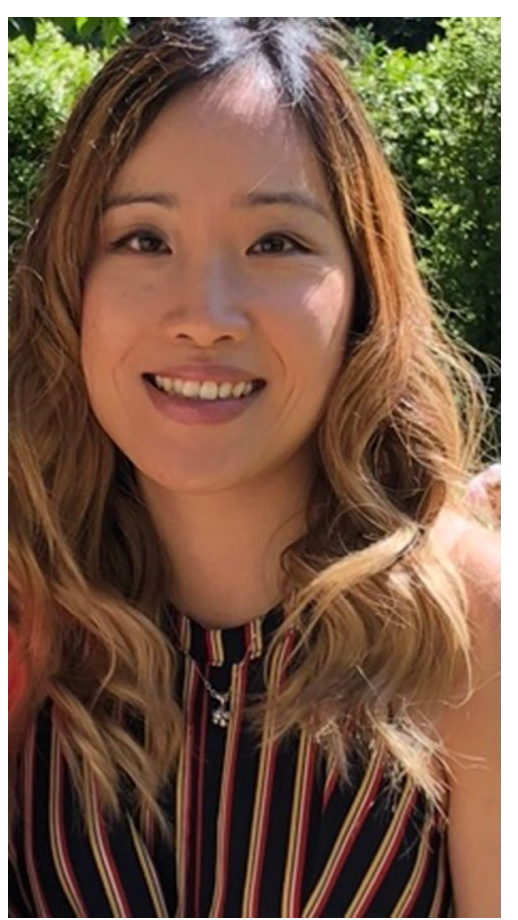

Publisher's Note Springer Nature remains neutral with regard to jurisdictional claims in published maps and institutional affiliations.

Wendy Zhou

wendyzhou16@gmail.com

1 Santa Clara Valley Medical Center, San Jose, USA 